\title{
Phenolic Contents, Oxidant/Antioxidant Potential and Heavy Metal Levels in Cyclocybe cylindracea
}

\author{
Mustafa Sevindik $^{* 1}$, Hasan Akgul ${ }^{1}$, Celal Bal ${ }^{2}$, Zeliha Selamoglu ${ }^{3}$ \\ ${ }^{1}$ Akdeniz University, Faculty of Science, Department of Biology, Antalya, TURKEY. \\ ${ }^{2}$ Gaziantep University, Oğuzeli Vocational School, Gaziantep, TURKEY. \\ ${ }^{3}$ Omer Halisdemir University, Faculty of Medicine, Department of Medical Biology, Nigde, TURKEY.
}

\begin{abstract}
Introduction: Mushroom species have been used for medical purposes and as nutrients since the old times. The present study aimed to determine phenolic content, antioxidant activity and heavy metal content of Cyclocybe cylindracea (DC.) Vizzini \& Angelini mushroom. Materials and Methods: Phenolic contents were screened with HPLC devices. TAS, TOS and OSI values were determined using Rel Assay kits. Heavy metal content were determined with atomic absorption method using an atomic absorption spectrophotometer. Result and Discussion: Gallic acid, hesperidin, catechin, syringic acid and hydroxybenzoic acid were detected in the mushroom. It was determined that the heavy metal content in $C$. cylindracea were generally at optimal levels and the TOS value of mushroom was high. Conclusion: $C$. cylindracea could be consumed as a good antioxidant source as long as it is obtained from safe areas.
\end{abstract}

Key words: Cyclocybe cylindracea, Antioxidant, Oxidant, Oxidative stress, Heavy metal, Phenolic contents.

\section{INTRODUCTION}

Most of mushroom species that could conduct a cosmopolitan life in all habitats could be consumed as food and for medical purposes because of their biological properties. ${ }^{1,2}$ Mushrooms are not preferred only for their texture and taste, but they are also rich in protein and amino acids and poor as a calorie source. ${ }^{3}$ In addition to their nutritional value, mushrooms were reported to have medical effects such as antibacterial, antiviral, antitumor, antioxidant, anti-inflammatory and immune system-booster. ${ }^{4-8}$

Mushrooms include many secondary metabolites such as phenolic compounds, polyketides, terpenes and steroids. ${ }^{9}$ It is known that these secondary metabolites show important medicinal properties in spite of lacking nutritive values. ${ }^{10}$ These secondary metabolites play a vital role in the antioxidant defense mechanisms of biological systems. ${ }^{11}$ Mushrooms can also help to reduce the effects of oxidative stress due to their antioxidant potential. Because of oxidative stress induced by free radicals, serious health problems such as neurological, cardiologic diseases, cirrhosis, diabetes, leukemia and necrosis may occur. ${ }^{12,13,14}$ Investigation of antioxidant activity and oxidative stress index of mushrooms as potent natural antioxidant used in inhibition of oxidative stress is very important to determination of new natural antioxidant materials.

Heavy metal contents in mushrooms are higher than agricultural plants, vegetables and fruits. ${ }^{15}$ Due to their saprotrophic properties, mushrooms can also be used as natural pollution indicators through element levels accumulated in their bodies due to substrate content during organic matter catabolism. ${ }^{16,17}$ Elements such as $\mathrm{Fe}, \mathrm{Co}, \mathrm{Cu}, \mathrm{Mn}, \mathrm{Mo}, \mathrm{Sr}, \mathrm{V}$ and $\mathrm{Zn}$ that are required for living organisms in trace amounts can accumulate in living organisms over time and lead to undesirable
Submission Date: 30-09-2017; Revision Date: 08-11-2017 Accepted Date: 08-12-2017

DOI: 10.5530/ijper.52.3.50 Correspondence: Dr. Mustafa Sevindik Department of Biology, Faculty of Science, Akdeniz University, Antalya, 51240 TURKEY.

Phone: +90-242- 3102348 E-mail: sevindik27@gmail. com

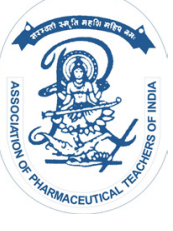

www.ijper.org 
consequences. ${ }^{18}$ Thus, to determine the element levels of mushrooms is important to avoid the health problems that may arise due to their consumption via the food chain.

The present study aimed to determine total antioxidant status (TAS), total oxidant status (TOS), oxidative stress index (OSI) and heavy metal contents (Fe, $\mathrm{Cu}, \mathrm{Zn}, \mathrm{Pb}$, $\mathrm{Ni}, \mathrm{Mn}, \mathrm{Co}, \mathrm{Cd}$ and $\mathrm{Cr}$ ) in Cyclocybe cylindracea (DC.) Vizzini and Angelini mushroom.

\section{Experimental}

Cycloybe cylindracea (DC.) Vizzini and Angelini mushroom samples were used in this study collected at Oğuzeli (Gaziantep Province / Turkey) region.

\section{Laboratory Studies}

The mushroom samples were dried at the incubator at $40^{\circ} \mathrm{C}$, then pulverized in a mechanical grinder, and $30 \mathrm{~g}$ samples were extracted with ethanol at $50^{\circ} \mathrm{C}$ for about $6 \mathrm{~h}$ in the soxhlet device (BUCHI Extraction System Model B-811). The extracts were concentrated under pressure with a rotary evaporator and were stored at $4^{\circ} \mathrm{C}$ until analyzed (BUCHI Rotavapor Model R-144).

\section{Determination of Phenolic Contents}

Extracted mushroom samples were processed with some modifications of the method developed by Caponio et al. ${ }^{19}$ using SHIMADZU system HPLC and DAD detector: Injection volume was adjusted to $20 \mu \mathrm{L}$. Acetic acid (3\%) was used as mobile phase $A$ and methanol was used as mobile phase B (Table 1) and the flow rate was regulated to $0.8 \mathrm{~mL}$ per min. Chromatographic separation was conducted with Agilent Eclipse XDB-C18 column $(250 \times 4.6 \mathrm{~mm}$ id $5 \mu \mathrm{M})$ at $30^{\circ} \mathrm{C}$.

\section{Determination of TAS, TOS and OSI Values}

The TAS and TOS values of the extracted mushroom samples were determined with Rel Assay brand kits (Rel Assay Kit Diagnostics, Turkey). Trolox was used as calibrator in identification of the TAS values and the results were given as mmol Trolox equiv./L. To determine the TOS values, hydrogen peroxide was used as calibrator and the results were obtained as $\mu \mathrm{mol} \mathrm{H}_{2} \mathrm{O}_{2}$ equiv. /L. ${ }^{20,21}$ The formula used to calculate OSI values is in the below: ${ }^{21}$

OSI $=\frac{\text { TOS, } \mu \text { mol } \mathrm{H}_{2} \mathrm{O}_{2} \text { equiv. } / \mathrm{L}}{\text { TAS, mmol Trolox equiv. } / \mathrm{L}} \times 100$

\section{Determination of Heavy Metal Levels}

The mushroom samples were dried in the incubator at $40^{\circ} \mathrm{C}$ and pulverized with a mechanical grinder, weighed and $1 \mathrm{~g}$ of samples were placed in $50 \mathrm{~mL}$ Erlenmeyer flasks in 3 replicates and $10 \mathrm{~mL} \mathrm{HNO}_{3}$ was added to the flasks and stored at room temperature for 24 to $48 \mathrm{~h}$. The stored erlenmeyer flasks were heated with a hot plate until the solution was cleared. Concentrated HCI $(10 \mathrm{~mL})$ was added to the heated erlenmeyer flasks and the firing process was repeated. After the firing process, $20 \mathrm{~mL}$ diluted $\mathrm{HCl}$ solution was added to the prepared solution, and the filtered solution was prepared for further analyses. ${ }^{22}$ The element contents of prepared solutions were determined with a Perkin Elmer (AAnalyst 400) device.

\section{RESULTS AND DISCUSSIONS}

\section{Phenolic Contents}

The phenolic compounds of C. cylindracea were determined using HPLC and the findings are shown in Table 2.

In context of investigations, 5 phenolic compounds were determined such as gallic acid, hesperidin, catechin, syringic acid and hydroxybenzoic acid. Phenolic compounds are known to have many activities, especially antioxidant activity. $^{23}$ In some studies, among the various polyphenols, it has been suggested that gallic acid (3,4,5-trihydroxybenzoic acid), a naturally occurring low-molecular-weight triphenolic compound, has strong antioxidant activities. ${ }^{24}$ Hesperidin, a member of the flavonoid group, is found in mushrooms such as Cordyceps sinensis and Ganoderma lucidum in addition to citrus species. ${ }^{25}$ It has been reported that hesperidin

\begin{tabular}{|c|c|c|c|c|c|c|c|c|c|c|c|c|}
\hline \multicolumn{10}{|c|}{ Table 1: HPLC gradient program. } \\
\hline Min & 0.1 & 20 & 28 & 35 & 50 & 60 & 62 & 70 & 73 & 75 & 80 & 81 \\
\hline$\% \mathrm{~A}$ & 93 & 72 & 75 & 70 & 70 & 67 & 58 & 50 & 30 & 20 & 0 & 93 \\
\hline$\% \mathrm{~B}$ & 7 & 28 & 25 & 30 & 30 & 33 & 42 & 50 & 70 & 80 & 100 & 7 \\
\hline
\end{tabular}

\%A: \% 3 Acetic acid,\% B: Methanol

Table 2: Phenolic contents of C. cylindracea.

\begin{tabular}{|c|c|c|c|c|}
\hline \multicolumn{5}{|c|}{ Table 2: Phenolic contents of C. cylindracea. } \\
\hline Gallic acid & Catechin & Sringic acid & Hydroxy benzoic acid & Hesperidin \\
\hline $2.17 \mathrm{ppm}$ & $12.71 \mathrm{ppm}$ & $1.72 \mathrm{ppm}$ & $6.48 \mathrm{ppm}$ & $75.58 \mathrm{ppm}$ \\
\hline
\end{tabular}




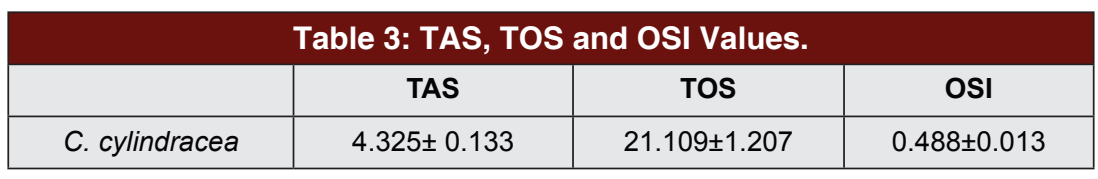

Values are presented as mean \pm S.D.; $\mathrm{n}=6$ (Experiments were made as 5 parallel)

\begin{tabular}{|c|c|c|}
\hline \multicolumn{3}{|c|}{ Table 4: Heavy Metal Contents. } \\
\hline Elements & Contents mg.kg $^{-1} \mathbf{\pm}$ Std & $\begin{array}{c}\text { Literature ranges } \\
\text { mg.kg-1 }^{-1}\end{array}$ \\
\hline $\mathrm{Fe}$ & $509,18 \pm 5,30$ & $14.60-835.00$ \\
\hline $\mathrm{Cu}$ & $60,33 \pm 5,60$ & $71.00-95.00$ \\
\hline $\mathrm{Zn}$ & $33,93 \pm 3,55$ & $29.80-158.00$ \\
\hline $\mathrm{Pb}$ & $16,54 \pm 0,93$ & $2.86-6.88$ \\
\hline $\mathrm{Ni}$ & $0,67 \pm 0,05$ & $1.18-5.14$ \\
\hline $\mathrm{Mn}$ & $47,82 \pm 1,05$ & $18.10-103.00$ \\
\hline $\mathrm{Co}$ & $5,47 \pm 0,20$ & $0.01-8.27$ \\
\hline $\mathrm{Cd}$ & $4,67 \pm 0,16$ & $2.71-7.50$ \\
\hline $\mathrm{Cr}$ & $9,63 \pm 1,44$ & $10.70-42.70$ \\
\hline
\end{tabular}

Values are presented as mean \pm S.D.; $n=3$ (Experiments were made as 3 parallel)

has antioxidant, antiallergic, anti-carcinogenic, antihypertensive, antimicrobial and vasodilator properties. ${ }^{26}$ Catechins exhibited significant antioxidant, anticancerogenic, anti-inflammatory, thermogenic, antimutagenic, probiotic and antimicrobial properties in the result of in vivo and in vitro studies. ${ }^{27}$ Syringic acid is known to exhibit multiple bioactive properties such as strong antioxidant, antiproliferative, antiendotoxic, antimicrobial, anti-inflammatory and anti-cancer effects. ${ }^{28}$ In a study, authors stated that hydroxybenzoic acid has antioxidant effect. ${ }^{29}$ In our work, high antioxidant activity is might be due to the presence of phenolic compounds as extracted from C. cylindracea samples.

In addition, it is suggested that this compound has a higher contribution to antioxidant activity because the highest value of the compounds detected is $75.58 \mathrm{ppm}$ of hesperidin. It should be evaluated separately antioxidant activities of the phenolic compounds identified in the same system to investigate the effective levels of the obtained compounds and to make certainly judgments.

\section{TAS, TOS and OSI Values}

TAS $(\mathrm{mmol} / \mathrm{L})$, TOS $(\mu \mathrm{mol} / \mathrm{L})$ and OSI values of $C$. cylindracea collected in Oguzeli (Gaziantep / Turkey) were determined with Rel Assay commercial kits and are presented in Table 3.

As seen in Table 3 TAS value of C. cylindracea was 4.325 $\mathrm{mmol} / \mathrm{L}$ and the TOS value was $21.109 \mu \mathrm{mol} / \mathrm{L}$. Also OSI value was 0.488 . In the previous study, it was found that TAS value of Tricholoma terreum (Schaeff.) mushroom samples collected from Mugla province was determined as 0.38 , TOS value of the same mushroom specie was 16.76 and OSI value was $4.41 .{ }^{22}$ In other studies, it was determined that the TAS value of Pleurotus eryngii (DC.) Quél was 1.93 and the TAS value of Auricularia polytricha (Mont.) Sacc. was $0.93 .^{30,31}$ In the present study higher TAS and TOS data of C. cylindracea were observed compared to previous studies. The high TAS value of C. cylindracea indicated that had its rich antioxidant potential. However, similarly higher TOS value indicated that higher amounts of oxidative agents presented in the mushroom due to environmental and metabolic factors. The OSI value, on the other hand, is the ratio of how much of the oxidant compounds produced by environmental and physiological processes in the structure of the living organism could be tolerated by antioxidant molecules that the organisms produced. The C. cylindracea OSI level was lower than that of $T$. terreum. These findings demonstrated that C. cylindracea was rich in antioxidant compounds that could neutralize oxidant molecules and could produce more antioxidant molecules compared to T. terreum. It was reported that the TAS levels of Omphalotus olearius (DC.) Singer fungi collected from different regions varied due to regional differences, although TAS values were close to each other. ${ }^{16}$ High TAS value of C. cylindracea obtained in the present study indicated that this mushroom could be used as a rich natural antioxidant source. However, when the TOS and OSI values are considered, it may be advisable to collect this mushroom from more adequate and pollutant-free regions.

\section{Heavy Metal Content}

$\mathrm{Fe}, \mathrm{Cu}, \mathrm{Zn}, \mathrm{Pb}, \mathrm{Ni}, \mathrm{Mn}, \mathrm{Co}, \mathrm{Cd}$ and $\mathrm{Cr}$ contents of C. cylindracea were determined with heavy metal analyses and presented in $\mathrm{mg} \cdot \mathrm{kg}^{-1}$. The heavy metal contents are demonstrated in Table 4 as Average \pm Std.

Mushrooms are also known to accumulate elements. ${ }^{16}$ The results of our studies conducted with previous study reported the lowest and highest element levels as 14.6-835.0 for $\mathrm{Fe}, 71.0-95.0$ for $\mathrm{Cu}, 29.8-158.0$ for $\mathrm{Zn}, 2.86-6.88$ for $\mathrm{Pb}, 1.18-5.14$ for $\mathrm{Ni}, 18.1-103.0$ for $\mathrm{Mn}$ and 2.71-7.50 mg.kg ${ }^{-1}$ for Cd levels of mushrooms. ${ }^{32}$

Furthermore, Co content was reported as 0.01-8.27 $\mathrm{mg} \cdot \mathrm{kg}^{-1}$ and $\mathrm{Cr}$ content was indicated as 10.7-42.7 $\mathrm{mg} \cdot \mathrm{kg}^{-1} \cdot{ }^{15,33} \mathrm{Fe}, \mathrm{Zn}, \mathrm{Mn}, \mathrm{Cd}$ and $\mathrm{Co}$ values obtained in our study were within the ranges mentioned above. It was observed that $\mathrm{Cu}, \mathrm{Ni}$ and $\mathrm{Cr}$ values were at the lower and $\mathrm{Pb}$ amount was at the higher. The higher $\mathrm{Pb}$ 
content could be due to the fact that the mushroom samples were collected at a roadside area.

\section{CONCLUSION}

Conducted analyses demonstrated that C. cylindracea samples collected at Oguzeli (Gaziantep / Turkey) region contained high levels of $\mathrm{Pb}$, while other heavy metal elements were at normal levels. In addition, bioactive phenolic compounds with antioxidant properties such as gallic acid, hesperidin, catechin, syringic acid and hydroxybenzoic acid have been identified in ethanolic extracts of the mushroom samples. It is suggested that this mushroom could be used as an effective and rich natural antioxidant supplement due to its high antioxidant potential. However, when $\mathrm{Pb}$ levels and TOS values are taken into account, it is recommended that these mushrooms should be obtained from cleaner and safer regions.

\section{CONFLICT OF INTEREST}

The Authors declare no conflict of interest.

\section{ABBREVIATIONS}

TAS: Total Antioxidant Status; TOS: Total Oxidant Status; OSI: Oxidative Stress Index; HPLC: High Performance Liquid Chromatography.

\section{REFERENCES}

1. Mdachi SJ, Nkunya MH, Nyigo VA, Urasa IT. Amino acid composition of some Tanzanian wild mushrooms. Food Chemistry. 2004;86(2):179-82.

2. Akata I, Ergonul B, Kalyoncu F. Chemical compositions and antioxidant activities of 16 wild edible mushroom species grown in Anatolia. International Journal of Pharmacology. 2012;8(2):134-8.

3. Sun L, Bai X, Zhuang Y. Effect of different cooking methods on total phenolic contents and antioxidant activities of four Boletus mushrooms. Journal of food science and technology. 2014;51(11):3362-8.

4. Mau JL, Lin HC, Song SF. Antioxidant properties of several specialty mushrooms. Food Research International. 2002;35(6):519-26.

5. Yang JH, Lin HC, Mau JL. Antioxidant properties of several commercial mushrooms. Food chemistry. 2002;77(2):229-35.

6. Tian Y, Zeng H, Xu Z, Zheng B, Lin Y, Gan C, Lo YM. Ultrasonic-assisted extraction and antioxidant activity of polysaccharides recovered from white button mushroom (Agaricus bisporus). Carbohydrate Polymers. 2012;88(2):522-9.

7. Jo EK, Heo DJ, Kim JH, Lee YH, Ju YC, Lee SC. The Effects of Subcritical Water Treatment on Antioxidant Activity of Golden Oyster Mushroom. Food and Bioprocess Technology. 2013;6(9):2555-61.

8. Acharya K, Ghosh S, Khatua S, Mitra P. Pharmacognostic standardization and antioxidant capacity of an edible mushroom Laetiporus sulphureus. Journal für Verbraucherschutz und Lebensmittelsicherheit. 2016;11(1):33-42.

9. Oke F, Aslim B. Protective effect of two edible mushrooms against oxidative cell damage and their phenolic composition. Food chemistry. 2011;128(3):613-9.

10. Vaz JA, Barros L, Martins A, Morais JS, Vasconcelos MH, Ferreira ICFR. Phenolic profile of seventeen Portuguese wild mushrooms. Food Science and Technology. 2010;44(1):343-6.

11. Palacios I, Lozano M, Moro C, D'arrigo M, Rostagno MA, Martínez JA, et al. Antioxidant properties of phenolic compounds occurring in edible mushrooms. Food Chemistry. 2011;128(3):674-8.
12. Choi Y, Lee SM, Chun J, Lee HB, Lee J. Influence of heat treatment on the antioxidant activities and polyphenolic compounds of Shiitake (Lentinus edodes) mushroom. Food Chemistry. 2006;99(2):381-7.

13. Vidović SS, Mujić IO, Zeković ZP, Lepojević ŽD, Tumbas VT, Mujić AI. Antioxidant properties of selected Boletus mushrooms. Food Biophysic. 2010;5(1):49-58.

14. Klaus A, Kozarski M, Niksic M, Jakovljevic D, Todorovic N, Stefanoska I, et al. The edible mushroom Laetiporus sulphureus as potential source of natural antioxidants. International journal of food sciences and nutrition. 2013;64(5):599-610

15. Zhu F, Qu L, Fan W, Qiao M, Hao H, Wang X. Assessment of heavy metals in some wild edible mushrooms collected from Yunnan Province, China. Environmental monitoring and assessment. 2011;179(1-4):191-9.

16. Sevindik M, Akgül H, Bal C. Determination of Oxidative Stress Status of Ompholatus olearius Gathered from Adana and Antalya Provinces in Turkey. Sakarya University Journal of Science. 2017;21(3):324-7.

17. Mleczek M, Niedzielski P, Kalač P, Budka A, Siwulski M, Gąsecka M, et al. Multielemental analysis of 20 mushroom species growing near a heavily trafficked road in Poland. Environmental science and pollution research international. 2016;23(16):16280.

18. Falusi BA, Olanipekun EO. Bioconcentration Factors of Heavy Metals in Tropical Crab ( Carcinus sp) From River Aponwe, Ado-Ekiti, Nigeria. Journal of Applied Sciences and Environmental Management. 2007;11(4):51-54.

19. Caponio F, Alloggio V, Gomes T. Phenolic Compounds of Virgin Olive Oil: Influence of Paste Preparation Techniques. Food Chemistry. 1999;64(2): 203-9.

20. Erel O. A novel automated direct measurement method for total antioxidant capacity using a new generation, more stable ABTS radical cation. Clinical biochemistry. 2004;37(4):277-285.

21. Erel O. A new automated colorimetric method for measuring total oxidant status. Clinical biochemistry. 2005;38(12):1103-11.

22. Akgül H, Nur AD, Sevindik M, Doğan M. Tricholoma terreum ve Coprinus micaceus' un bazı biyolojik aktivitelerinin belirlenmesi. Artvin Çoruh Üniversitesi Orman Fakültesi Dergisi. 2016;17(2):158-62.

23. Saxena M, Saxena J, Pradhan A. Flavonoids and phenolic acids as antioxidants in plants and human health. Int. J. Pharm. Sci. Rev. Res. 2012;16(2):130-4.

24. Badhani B, Sharma N, Kakkarasid R. Gallic acid: a versatile antioxidant with promising therapeutic and industrial applications. RSC Adv. 2015;5(35):27540-57

25. Bhardwaj A, Pal M, Srivastava M, Tulsawani R, Sugadev R, Misra K. HPTLC Based Chemometrics of Medicinal Mushrooms. Journal of Liquid Chromatography and Related Technologies. 2015;38(14):1392-406.

26. Wilmsen PK, Spada DS, Salvador M. Antioxidant Activity of the Flavonoid Hesperidin in Chemical and Biological Systems. J. Agric. Food Chem. 2005;53(12):4757-61.

27. Mansour MK, Ibrahim EM, El-Kholy MM, El-Madawy SA. Antioxidant and histopathological effect of catechin and neem leaves extract in acrylamide toxicity of rats. Egypt. J. Comp. Path. and Clinic. Path. 2008;21(1): 290-313.

28. Cikman O, Soylemez O, Ozkan OF, Kiraz HA, Sayar I, Ademoglu S, et al. Antioxidant Activity of Syringic Acid Prevents Oxidative Stress in I-arginineInduced Acute Pancreatitis: An Experimental Study on Rats. Int Surg. 2015;100(5):891-6.

29. Farhoosh R, Johnny S, Asnaashari M, Molaahmadibahraseman N, Sharif A. Structure-antioxidant activity relationships of o-hydroxyl, o-methoxy, and alkyl ester derivatives of p-hydroxybenzoic acid. Food Chemistry. 2016;194: 128-34.

30. Yildirim NC, Turkoglu S, Yildirim N, Kaplan Ince O. Antioxidant properties of wild edible mushroom Pleurotus eryngii collected from Tunceli province of Turkey. Digest Journal of Nanomaterials and Biostructures (DJNB). 2012;7(4):1647-54.

31. Avci E, Cagatay G, Avci GA, Cevher SC, Suicmez M. An Edible Mushroom With Medicinal Significance; Auricularia polytricha. Hittite Journal of Science and Engineering. 2016;3(2):111-6.

32. Mallikarjuna SE, Ranjini A, Haware DJ, Vijayalakshmi MR, Shashirekha MN, Rajarathnam S. Mineral composition of four edible mushrooms. Journal of Chemistry. 2013;1:1-5

33. Svoboda L, Chrastný V. Levels of eight trace elements in edible mushrooms from a rural area. Food Additives and Contaminants. 2008;25(1):51-8. 


\section{PICTORIAL ABSTRACT}

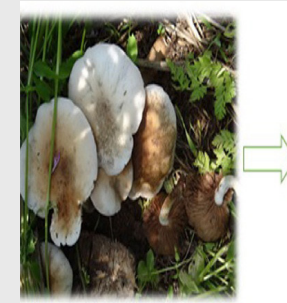

Cyclocybe cylindracea

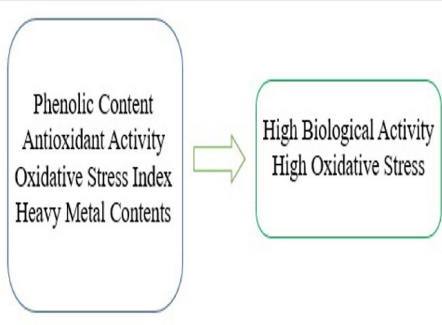

Oxidative Stress Index
High Biological Activity

Oxicative Stress

\section{About Authors}

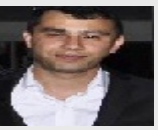

Dr. Mustafa Sevindik: He received his PhD from the Department of Biology at Akdeniz University. His research area includes medicinal mushroom, mushroom systematics, antioxidant, antimicrobial and biological activities.

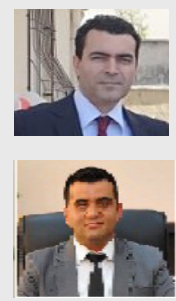

Dr. Hasan Akgül: He has been working as a associate professor in the Biology Department of Akdeniz University. His research interests include medical fungus, fungus systematics, antioxidants and antimicrobials

Dr. Celal BAL: He has been working as a lecturer in the Gaziantep University. His research interests include medical fungus, fungus systematics, antioxidants and antimicrobials.

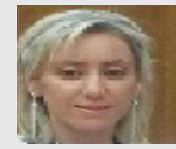

Prof. Dr. Zeliha Selamoglu: She has been working as a professor in the Nigde Omer Halisdemir University. Her research interests include antioxidants and oxidative stress.

Cite this article: Sevindik M, Akgul H, Bal C, Selamoglu Z. Phenolic Contents, Oxidant/Antioxidant Potential and Heavy Metal Levels in Cyclocybe cylindracea. Indian J of Pharmaceutical Education and Research. 2018;52(3):43741. 